\title{
Arbor
}

\section{Angélica y el desencadenamiento de la locura: Lope de Rueda y Tirso de Molina}

\section{Alfredo Hermenegildo}

Arbor CLXXVII, 699-700 (Marzo-Abril 2004), 623-637 pp.

La locura, como recurso dramático, aparece en dos obras separadas por unas cuantas décadas: la Medora, de Lope de Rueda, y La villana de la Sagra, de Tirso de Molina. En la primera, la presencia destructora y conflictiva de unos hermanos gemelos desencadena la locura de unos individuos, los padres de la protagonista, que alteran con sus andanzas la convivencia social del grupo a que pertenecen. La fiesta carnavalesca está también en la base misma de la construcción de los locos. En la obra de Tirso, la locura del galán, de don Luis, es utilizada para detener, con su fondo libresco, el desarrollo previsible de la fábula. Esta locura sólo tiene connotaciones de orden psiquiátrico, y no genera el espíritu festivo que alimenta la Medora. Además, en La villana la locura no hace más que provocar una alteración superficial y marginal del orden de la historia. La obra tirsiana usa la locura como puro divertimiento literario y no logra integrarla de manera eficaz en la economía general de la dramatización.

«La sensatez no conviene en todas las ocasiones; a veces hay que ser loco con los locos.»

(Menandro)

La presencia del nombre de Angélica y todas las connotaciones literarias que le acompañan están en el origen de la dramatización, de las 


\section{Alfredo Hermenegildo}

tensiones internas que alimentan y conforman dos obras del Siglo de Oro, la comedia Medora, de Lope de Rueda, y La villana de la Sagra, de Tirso de Molina. En aquella, al nombre de Angélica se añade el de Medoro. En ambas se desencadena la locura de unos individuos -Acario y Barbarina, en la primera, y don Luis en la segunda-, que alteran la convivencia social del grupo que vive en torno a ellos. Los caminos y los métodos de construcción de la fábula son distintos en uno y otro caso. La importancia y la integración de la locura en Medora y en La villana de la Sagra tienen diferente calado. En la primera, es la piedra angular del edificio. En la segunda no pasa de ser un añadido imperfectamente insertado en la diégesis. Por otra parte, la locura que invade las dos obras, total o parcialmente, es de dos órdenes. La obra de Rueda se construye en torno al desequilibrio colectivo producido por unos hechos anteriores al comienzo de la acción dramática, desequilibrio surgido de la presencia de unos hermanos gemelos y que está teñido, al mismo tiempo, con los colores de la fiesta popular, del carnaval. La comedia tirsiana usa la locura para detener, momentáneamente, el flujo y el recorrido normal de las aguas dramáticas, locura que sólo tiene connotaciones de orden psiquiátrico y no generan en modo alguno el espíritu festivo que alimenta la Medora. Por otra parte, en esta última, la locura modifica la vida social de forma profunda y determinante, mientras que en La villana de la Sagra no produce más que una alteración superficial y casi marginal. Esa es la hipótesis de nuestro trabajo. En los dos casos quedan neutralizados los efectos del desequilibrio individual y colectivo, produciéndose el final feliz requerido por la comedia.

Estamos en el mundo de la creación literaria y todo en él está relacionado. El diálogo entre los textos atraviesa las fronteras y los tiempos. Por eso hay que recordar una locura célebre en el Renacimiento italiano, la de Orlando en el Orlando furioso, de Ariosto. La obra tuvo en España, inmediatamente después de su publicación, cuatro traductores: Jerónimo de Urrea, Hernando Alcocer, Vázquez de Contreras y Nicolás de Espinosa. Y engendró una numerosa descendencia, que ha sido estudiada meticulosamente por Maxime Chevalier, en su L'Arioste en Espagne (15301650): recherches sur l'influence $d u$ "Roland furieux. No entraremos en ese problema ahora, Bástenos recordar que la locura ariostesca flota en el ambiente literario del Quinientos español. Pero no hay que descartar de nuestra reflexión otra locura encarnada en un personaje dramático que perdura desde los tiempos del hispano-romano Séneca. Es la de Hércules, héroe de la tragedia Hercules furens, que pierde el control de sus facultades mentales, después de haber sido envenenado con la túnica que le dio Deyanira, su esposa. La obra senequiana y la locura de Hércules 
están presentes, por ejemplo, en la Tragedia Lucifer furens in diem Circuncisionis Domini, del año 1563, versión a lo divino de la obra romana, escrita dentro del marco de las actividades pedagógicas de los colegios jesuíticos del siglo XVI. Y hay que tener en cuenta, también, la tragedia Atila furioso, del valenciano Cristóbal de Virués, en la que el origen de la locura producida por el veneno administrado al héroe está claramente identificada con el Hercules furens de Séneca.

Se trata, en todos los casos apuntados, de graves desequilibrios psíquicos producidos por un acontecimiento preciso o por la intervención de un personaje que provoca, por medio del veneno o su soporte -la túnica, por ejemplo- la descompensación absoluta de las facultades mentales del héroe.

Pero vengamos a nuestras dos piezas dramáticas. La primera, la $\mathrm{Me}$ dora, del segundo tercio del siglo XVI. La segunda, La villana de la Sagra, de la primera mitad del siglo XVII. Los modelos dramáticos habían cambiado. Las preocupaciones estéticas, también. La conformación del público espectador, aún más. En esos dos contextos, el uso de la locura como instrumento de organización de la fábula se lleva a cabo de dos modos distintos. Son, en realidad, dos locuras que tienen fines diversos y que llevan a metas diferentes.

¿Qué entendemos por locura, desde la perspectiva de la búsqueda de una interpretación del uso literario de la misma?

Covarrubias, en su Tesoro de la lengua castellana o española, define al loco como «el hombre que ha perdido su juyzio», y señala que una de las posibles raíces del término «loco» está en el latín «loquendo», «porque los tales suelen, con la sequedad del celebro, hablar mucho y dar muchas vozes». A don Alonso Quijano también se le secó el cerebro.

Ahora bien, la locura es un enfermedad muy variada. Una de sus manifestaciones es la psicosis delirante aguda, que, por otra parte, es un conjunto de desequilibrios y de alteraciones psíquicas que ni podemos ni queremos analizar aquí. Se trata de un trastorno fundamental de la personalidad. Los que la padecen tienen frecuentemente el sentimiento de estar controlados por fuerzas extrañas. Poseen ideas delirantes y alucinaciones, que pueden ser extravagantes, con alteración de la percepción, afecto anormal sin relación con la situación del entorno, y autismo entendido como aislamiento. El deterioro de la función mental en estos enfermos alcanza un grado tal que condiciona la existencia misma del yo y su capacidad de afrontar algunas de las demandas ordinarias de la vida o de mantener un adecuado contacto con la realidad. El psicótico acaba "no viviendo» en el mundo que le rodea. Hay una disociación entre la realidad ambiente y la percepción que él tiene de «sus alrededores perso- 
nales», ya que en su desarreglo mental hay una negación inconsciente de los seres y situaciones que le envuelven.

El enfermo no piensa ni razona de forma normal. La actividad cognitiva del psicótico no es lógica, está llena de incoherencias y desconexiones, cosa que tiene una gran repercusión en el lenguaje utilizado. No posee conciencia de su enfermedad. Hay en él alucinaciones, es decir, percepciones de lo que no existe, y que pueden afectar a todos los sentidos, principalmente el oído, la vista y el tacto. Las ideas delirantes son auténticas alteraciones del pensamiento, ideas falsas e irreductibles por la presión de razonamiento del otro. Su lenguaje es desorganizado e incoherente, y suele expresar ideas de persecución, de grandeza, de celos o de religiosidad pervertida. Una de las características más frecuentes entre este tipo de psicotizados es la desrealización o sensación de extrañeza frente al mundo externo, que por su proximidad y cotidianeidad debería ser fácilmente reconocible. El entorno aparece al enfermo como algo nebuloso, irreal, extraño e insólito.

Ahora bien, esta forma de locura, perfectamente identificable en el individuo, puede ser provocada por la acción de un agente externo, los celos desencadenados en una relación amorosa, por ejemplo, o por la influencia de un ambiente en el que domina la ruptura de las coordenadas que estructuran el orden dominante. Es el caso de los individuos envueltos dentro de la ola de desenfreno provocada por el fenómeno conocido como fiesta popular o situación colectiva marcada por la carnavalización.

La figura del loco de la fiesta popular, el simple o el bobo, son signos utilizados frecuentemente en la obras dramáticas. Para acercarnos a la descripción de estas figuras, teniendo en cuenta que el modelo general subyacente es el que organiza la construcción del loco festivo, hemos recurrido a las conocidas reflexiones de Mijaíl Bajtín en L'oeuvre de François Rabelais et la culture populaire au Moyen Age et sous la Renaissance. Sobre el personaje emblemático de la fiesta popular y las formulaciones que sobre dicha figura hicimos en nuestros Juegos dramáticos de la locura festiva, no vamos a volver ahora. Sirva sólo de recordatorio la figura del loco como signo representativo de la otra cara del mundo, la de la parodia, la burlesca, la que se señala como opuesta a la cara oficial. El loco, con su pasión por la comida, la bebida, el dormir, el uso de un lenguaje obsceno, la renunciación ostensible a las exigencias sociales dominantes -la honra, por ejemplo-, etc., es una constante sémica que se manifiesta de maneras variadas en las obras dramáticas. El rasgo determinante del realismo grotesco es el rebajamiento de todo lo que es elevado y espiritual, ideal y abstracto, a un nivel material y corporal, subrayado como bajo. La exaltación de lo grosero y de las activi- 
dades biológicas que constituyen la base misma del mecanismo propio de la renovación del ser humano y del mundo, es percibida por el discurso dominante como rebajamiento. Pero dicho rebajamiento supone un acercarse a la tierra, un comulgar con la tierra entendida como principio de nacimiento, de absorción y de regeneración. El loco grotesco es la afirmación del carácter real, cotidiano, íntimo, del ser humano. Y al mismo tiempo, en ese acercamiento a la tierra hay un deseo de horizontalidad, de igualación con los varios componentes de la naturaleza, personas, animales o cosas. De ahí la zoomorfización o animalización y la reificación o cosificación a que son reducidas con frecuencia las figuras humanas del carnaval. O la antromorfización a que se someten las figuras animales o incluso los objetos inertes de la naturaleza.

En ese proceso de carnavalización del espacio dramático, proceso encarnado en las figuras de los bobos, los graciosos, los bufones, los pastores rústicos, etc., se introduce en la pieza un aire de locura que acaba contagiando a otros personajes pertenecientes al espacio de lo serio y lo oficial. De tal modo que la divina y creadora locura colectiva de quienes se sitúan, en un tiempo y un espacio limitados por el discurso dominante, al margen de la oficialidad y asumen provisionalmente los papeles preponderantes en la sociedad, acaba contagiando a los personajes pertenecientes al mundo oficial. Y es ahí donde surge otro tipo de locura. El caballero, el señor, el dominador, acaba siendo arrastrado al espacio del carnaval por vía de la burla, de la parodia, de lo grotesco. Actúa, a partir de ese momento, como si hubiera perdido la capacidad de autocontrol y estuviera dominado por un extraño trastorno psíquico, que se parece al que surge en algunos casos de enfermedad mental bien definidos por la ciencia médica.

El individuo normal, dominado y sometido al proceso de carnavalización, pierde el control de su propia individualidad, cesa de ser quien era y se deja arrastrar por la ola de transformaciones sociales y burlescas. El problema es que el período de carnavalización puede acabar, puesto que se desarrolla en un tiempo y un espacio limitados, pero la alteración psíquica del señor sigue vigente, hasta que en la pieza dramática se modifique radicalmente la situación, por medio de la llegada de un final feliz o por la intervención de un «deus ex machina», capaz de restablecer la situación inicial o de provocar la aparición de una nueva. Los síntomas de su «locura» tienen síntomas parecidos a los de la psicosis delirante aguda descritos más arriba. Además del deterioro de la función mental, de la disociación de la realidad y del mundo interior del enfermo, de las incoherencias y desconexiones típicas, aquí se produce también una profunda alteración en el lenguaje, recogida perfectamente en los textos literarios. 
Garapon ha descrito bien lo que ha llamado «fantasía verbal», es decir, la aparición de un lenguaje que rompe las reglas de la comunicación social y se pone al margen de lo que la comunidad acepta y es capaz de descodificar. Es el juego verbal, liberado de la preocupación por el significado y puesto bajo el signo de la gratuidad. El grito de libertad que implica la destrucción de la norma lingüística dominante, la incomprensibilidad de lo dicho y no-dicho-, y el hermetismo semántico de numerosos juegos de palabras puramente gratuitos, hacen de estos signos una manifestación más de la locura liberadora propia de la fiesta popular. Los signos carnavalescos se extienden hasta ocupar el espacio propio de la norma lingüística. La trasgresión de la regla dominante llega hasta los límites de la comprensión. O de la incomprensión. Importa menos la descodificación de este signo o de aquel otro, que la difusión de ese espíritu de magma en ebullición regeneradora. El loco de la fiesta popular recurre al uso de la fantasía verbal, con lo que tiende a aislarse, en un proceso de autismo festivo, del medio que le rodea y que es incapaz de descodificar los mensajes que nuestro personaje emite. En el caso del «señor carnavalizado», la confusión, la disociación de la realidad y de su mundo interior, se manifiesta también en el uso de una fantasía verbal que, por otra parte, tiende a convertirle de modo más rotundo en signo y objeto inerte de la burla, de la parodia y del ridículo.

Lo mismo que en la otra forma de locura descrita, que a veces se desencadena a causa del golpe producido por una mala experiencia amorosa, por unos celos inesperados, en el síndrome de los efectos producidos en el entorno oficial por la fiesta popular también aparecen unos síntomas de psicosis que alteran, modifican y rebajan al personaje hasta los límites de la destrucción, de la aniquilación total.

La dos obras dramáticas que estudiamos tienen un punto común, es la presencia de un personaje llamado Angélica, nombre que une las dos piezas a la tradición textual del Orlando enamorado de Ariosto. La simple invocación y la presencia de tal nombre condiciona y, diríamos que obliga, la aparición de la locura en las dos fábulas. Es el elemento mágico que, inscrito en la cadena textual con unas determinadas connotaciones, impone en los dos ejemplos de nuestro corpus la necesidad de dramatizar el proceso de psicotización de ciertos personajes. En el caso de $L a$ villana de la Sagra, se invoca la figura del héroe ariostesco de manera directa. Luego lo veremos. Pero en la Medora, la situación es más compleja.

Hay en la comedia de Rueda dos figuras, Angélica y Medoro, que coinciden nominalmente con las que habitan el poema de Ariosto, aunque aquí no se trate de dos amantes, sino de dos hermanos gemelos, de ex- 
traordinario parecido. Es decir, el nombre de Angélica -y de Medoro- proporciona el impulso inicial para poner en marcha una situación en que la locura será un elemento estructurante de la dramatización. Ahora bien, la manera de provocar la conmoción social y la alteración del orden establecido en la célula familiar y colectiva, es distinta. Se pasa por una causa mediadora: la existencia de los gemelos, que en las tradiciones de las primitivas comunidades humanas han sido siempre causa de enfrentamientos, de guerras, de crímenes y de alteraciones de la vida colectiva. La locura sugerida por el solo nombre de Angélica es provocada de modo inmediato por la presencia de los gemelos. No hay aquí una tormenta de celos desencadenante de la crisis psicótico-delirante. Repetimos que Angélica y Medoro no son amantes, sino hermanos, y que no hay en su relación mutua ninguna connotación amorosa. Pero es su condición geminal la que desequilibra el estado psíquico de la célula familiar y la locura de los padres de ambos, Acario y Barbarina, arrastrados y contaminados por el torrente de la otra locura, la festiva, la del carnaval, la que vive el personaje del simple, del bobo.

Dos palabras sobre el problema de los gemelos como agentes de la perturbación social.

En la Medora hay una situación inicial en la que existen dos hermanos gemelos y sorprendentemente parecidos. En la tradición mítica se ha identificado una manera de prevenir y controlar el carácter recurrente de la violencia sagrada haciendo uso de la prohibición y el entredicho, y organizando la ritualización de la violencia, el rito violento. Con ello se ha querido impedir el desencadenamiento de la violencia real, la no ritual, la mimética. Las principales prohibiciones -entredicho de objetos, entredichos sexuales y alimentarios, etc.-organizan el espacio religioso de las comunidades humanas. Y uno de los entredichos, una de las prevenciones colectivas, es el que define la existencia de los iguales, de los parecidos, de los gemelos, de lo especular, como virtualmente malo y generador de tensión dentro de la colectividad. De ahí el temor mítico a la geminidad.

Dentro de esa tradición se debe situar el núcleo generador de la dramaticidad en la Medora. Acario y Barbarina tienen dos hijos gemelos. Su existencia crea problemas colectivos. El primero es el rapto del niño Medoro por la gitana. Con este gesto se tendría que haber roto el maleficio familiar, puesto que uno de los gemelos había desaparecido y la comunidad se había liberado de la causa de su desgracia. Pero Medoro vuelve a hacerse presente, bajo nuevas formas (Armelio, Armelia), y sólo se solucionará el problema cuando la condición geminal de ambos hermanos ceda el paso a un nuevo estatuto social. Angélica se casará con Casandro 


\section{Alfredo Hermenegildo}

y ya no será «gemela» sino «esposa». Con lo que el peligro habrá sido conjurado.

Rueda, sobre esta tela de fondo, ha tejido una comedia donde surge un gran número de conflictos que ocultan y hacen olvidar la célula germinal. $\mathrm{Y}$ aquí es donde entran en juego los enfrentamientos entre los actantes de los espacios señorial y ancilar, de los varios subespacios ancilares opuestos consigo mismos y entre unos y otros, y el espacio de la gitana y Armelio.

El primer enfrentamiento es el que opone a Acario/Barbarina, los viejos padres de Angélica, con la gitana. El espacio de la gitana y Medoro/Armelio queda definido por la relación [madre/hijo]. Su carácter incierto y su condición poco determinada están marcados en la intención expresada por la gitana: es «menester de buscar la vida entre las nobles personas» ${ }^{1}$ (p. 223). Sobre la existencia del drama lejano de las «nobles personas» (los que perdieron el hijo), se cierne una nueva amenaza. La gitana y Armelio van a invadir el espacio señorial cuando llegan a «el pueblo tan desseado por nosotros» (p. 223), en el que se encuentra el «portal de Ruçafa» (p. 224). La gitana está atando la acción de la comedia a un lugar en que la compañía de cómicos peregrinos sólo está de paso, Valencia.

Cuando se acerca la gitana al espacio señorial, el objeto disputado será la identidad misma de Medoro. Es decir, la dramaticidad de este conflicto es la primera consecuencia de la existencia del problema de la geminidad. Y el conflicto se solucionará con la anagnórisis, el reconocimiento final de la identidad de Armelia/Medoro, y con la destrucción de la pareja geminal por medio de la boda de Angélica con Casandro. Angélica deja así de ser gemela y pasa a ser esposa. La tensión producida por los hermanos parecidos ha dejado de alterar la convivencia colectiva.

Pero antes de llegar al final feliz, el espacio señorial, lesionado en su base por el problema de los gemelos, ha estallado. Es un mundo que carece del decoro que le es propio. Acario rompe el orden espacial, abandona toda preocupación inherente a su condición social y abre un paréntesis en su existencia dentro del que va a vivir él y hacia el que va a arrastrar a todos los personajes de la comedia. Acario, hombre maduro o, quizás, viejo, se enamora de una muchacha joven, Estela, y provoca la reacción en cadena de la serie de personajes que pueblan la obra. Con la acción de Acario el espacio señorial se convierte en el espacio de lo inconveniente, de la burla, de la parodia, y sólo se recupera el decoro que le es propio al final de la comedia. Pero mientras tanto se ha puesto en marcha la serie de tensiones dramáticas que comentamos a continuación. Acario y su mujer, Barbarina, pierden el control de sus vidas y se ven envueltos en una extraña locura. 


\section{Angélica y el desencadenamiento de la locura...}

Una vez roto el decoro familiar y social, los dos viejos son absorbidos por el discurso carnavalesco que encarna el lacayo Gargullo, el simple, y se manifiestan como seres perdidos en la soledad de su psicosis, una vez alejados de lo que la práctica social imponía a sus personas. Así habla Acario de la pérdida de su identidad propia: «Un moço tan descuidado como es aqueste Gargullo hame hecho vestir con aquel leñador y m'astusar la barba para parescer otro de lo que soy, y también por ir como debo para hablar con aquella caríssima de más que querubín de yesso y más blanca que la misma leche que de las vericundas lechugas sale cuando acaso con los iracundes dientes del simplecíssimo burro son cortadas. $¡ O h$, cuerpo del cielo, qué pedaço de retórica he dicho sin tenella pensada ni estudiada! ¡Oh, qué haze el amor! ¡Oh, qué vivos haze a los agudos, y tibios los lerdos y floxos, y qué avisados a los sabios! Pardiez, si agora fueran vivos Aristómilis o Plutón, no me dexe Dios medrar con los amores de mi señora Estela si no me entrara en un cércol con ellos a disputar. ¡Oh, qué lenguarazo estó! Y ansí ha de ser ello, porque, cuando estuviere delante mi señora Estela, sepa hablar desenvueltamente y no como otros alforjas que se atan como correa de çapato. Pero, iqué digo!, gran tardança es la que ha hecho este mi moço» (p. 227).

Disfraz de leñador, nueva compostura de la barba, transformación del lenguaje normalizado en un párrafo considerado por él mismo, en un momento de lucidez, como un "pedazo de retórica», y en el uso de formas burlescas y carnavalizadas de nombres propios del discurso culto y oficial, Aristómilis y Plutón -por Platón-. Es el mismo lenguaje que utilizan los lacayos inmersos en el discurso carnavalesco (el criado Ortega remeda el discurso eclesiástico, oficial, cuando dice beato mórtoris qu'in Dólime morieta (p. 225) y que encubren la fantasía verbal de la locura colectiva.

La forzada y aceptada transformación de Acario también aparece cuando se presenta a la puerta de la casa de la joven Estela, de quien anda enamorado. De nuevo confiesa que «hanme aconsejado que me arme de punta en blanco y me ponga a la puerta de este bellaco de Lupo, padrastro de mi señora Estela» (p. 237). Con la pérdida de su identidad, transformado por un amor ridículo, Acario es víctima de una psicosis que le lleva a la marginación social, a ser castigado por los golpes demoledores de Lupo y transformado en animal de carga, cuando lleva al hombro al falsamente castigado Gargullo por la paliza de Lupo. Era Acario el que recibía los «correonazos» y quien, a continuación, transportaba a cuestas al burlón y pseudoherido lacayo. La última transformación del enloquecido Acario es la que se produce cuando Lupo le mete en un saco y le deposita encima de una tumba del cementerio. El viejo aparece como «un 
asno» (p. 247) dando gritos histéricos, según palabras del propio Gargullo. El rebajamiento carnavalesco de Acario ha producido en él una crisis de aislamiento, de identificación propia, de decoro personal, característica de los estados psicóticos delirantes. Pero todo ello quedará neutralizado cuando se descubre la verdadera identidad de Medoro, el hermano perdido y robado por la gitana, y la boda de Angélica y Casandro.

El caso de Barbarina es, tal vez, más significativo. Se deja llevar también, como Acario, por la imposición de los otros, en este caso de Águeda, quien le «ha mandado que vaya vestida en este hábito» (p 245), es decir, que renuncie a su forma de estar en sociedad. Siguiendo dichas condiciones, lleva una existencia aislada, anormal, impropia de su edad y de su condición social. Sin que haya un apunte directo en la obra, la locura y el desvío psicológico de Barbarina surge de la existencia de sus dos hijos gemelos. Y cuando Medoro, el desaparecido, vuelve a surgir en la comunidad, Barbarina manifiesta todo su desequilibrio interior. La propia Angélica dice de su madre que «está ocupada en sacar agua de sus alambiques» (p. 219), y que "se ha encomendado también a Águeda, la cual le ha dicho que le traiga agua de siete fuentes y la tierra de siete muertos por hazer ciertas cosas, y ella lo comiença a poner por obra. De más d'esso, nunca entiende sino en exalbergarse aquel rostro, enrojarse aquellos cabellos, polirse aquellas manos, que no paresce muchas vezes sino disfrez $[$ sic] de carnestoliendas» (p. 220). La conexión entre el disfraz, los afeites y la ocupación de Barbarina, y el carnaval, establecen bien el contacto entre las dos locuras, la sublime y vivificante de la fiesta popular, y la destructora y alienante de la vieja madre de Angélica. El criado Ortega, cuando se encuentra en la calle con su ama, tiene esta un aspecto tal que es tachada de "pantasma" varias veces (p. 246) por el lacayo. Y la aislada y, en cierto modo, destruida personalidad de Barbarina, anuncia que va «a seguir mi romiage por esta encrucijada» (p. 247). El delirio y las alucinaciones de la vieja se hacen signo dramático cuando encuentra en el cementerio a Acario, que sale del saco armado como caballero, tal como hemos señalado más arriba. Y la vieja corre enloquecida gritando que «el diablo viene tras de mí armado» (p. 248). Todo se resuelve. La psicosis de Barbarina desaparece cuando la gitana cuenta la historia del rapto de Medoro, el hijo reencontrado, y se fijan las bodas de Angélica y Casandro. El maleficio se ha roto y la paz vuelve al conjunto social. La psicosis delirante ha sido neutralizada cuando la presencia de los gemelos, como signo vigente, ha dado paso a la nueva situación. La locura ha sido una manera de enredar y de complicar la fábula, para poder resolver el embrollo tan pronto como la causa primera ha desaparecido. Y todo ello, todo el problema de la locura personal de los dos viejos, está 
Angélica y el desencadenamiento de la locura...

envuelto en los trazos grotescos de la fiesta del carnaval, personificada por Gargullo, Ortega y otros lacayos.

En la Medora ruedesca, la locura tiene un papel estructurante de mucha importancia. El caso de La villana de la Sagra es completamente distinto. Es cierto que la presencia de una mujer llamada Angélica, la heroína, provoca irremediablemente la presencia inevitable de la locura de tradición ariostesca. Pero en la comedia de Tirso de Molina, la función de la psicosis es poco consistente en la economía general de la fábula. Parece como si el autor se hubiera sentido obligado a introducir un segmento con la locura de un personaje, don Luis, aunque dicho segmento tenga una eficacia dramática de poca trascendencia en el conjunto de la diégesis. Veamos cómo se integra en la obra el momento de la locura.

No describiremos aquí el contenido de la comedia. Baste recordar que Angélica, la villana de la Sagra, ha estado a punto de ser raptada por el comendador don Pedro en la romería de san Roque. Don Luis, el protagonista, abandona su tierra gallega, después de haber asesinado a un compañero de juego de cartas, juego al que tiene una profunda adicción. Mas tarde interviene y evita el rapto de la heroína haciendo huir al fracasado secuestrador. Don Luis, perdidamente enamorado de la muchacha y disfrazado de criado, entra al servicio del padre de Angélica. Y cuando todas las dificultades parecen haberse resuelto y la comedia se encamina hacia el final feliz, se produce una crisis tardía que está a punto de dar al traste con la felicidad amorosa de los protagonistas.

Angélica ha visto y oído cómo don Luis decía a doña Inés, su hermana, vestida de paje, algunas frases que ella misma sólo podía descodificar erróneamente, ya que no estaba en posesión de la clave necesaria. La villana ignora que Guzmán/doña Inés es hermana de don Luis. Sabe que Guzmán es mujer, pero cree que es una supuesta dama de Valladolid, doña Juana, burlada por don Pedro. Angélica oye que don Luis llama a Guzmán/doña Juana/doña Inés «luz clara de aquestos ojos» (v. 2811²), al tiempo que le pide los brazos (v. 2816). Doña Inés le contesta que «los dos hemos de casarnos» (v. 2828), aludiendo a las dos bodas que ambos hermanos pueden llevar a efecto. La falta de comprensión del mensaje por parte de Angélica le hace vivir una tensión muy fuerte de celos y a renunciar a su enlace con don Luis, acusándole (v. 2868) de traidor. Los celos de Angélica son claramente desmesurados, ya que desarticulan un largo proceso de acercamiento amoroso que organiza toda la obra. Proceso que se neutraliza por un innecesario malentendido. Y aquí entra en juego la dramatización de la locura de don Luis.

$\mathrm{Al}$ verse rechazado por Angélica, el galán invoca, en un largo parlamento, a los cielos, el sol, la luna, las estrellas, el mar, los animales, las 
aves, los peces, todos ellos contaminados por su propia demencia. Y termina, antes de quitarle la espada a don Pedro y de salir en persecución del resto de los personajes, en una anáfora muy característica del teatro barroco. Recuérdese el famoso monólogo de Segismundo en la calderoniana La vida es sueño. Dice así don Luis:

«Cielos, sol, estrellas, luna, agua, tierra, fuego, viento, animales, peces, aves, montes altos, valles, cerros, celos me han vuelto loco, porque celos acabarán mi vida con el seso.

Hoy Toledo verá un loco que, escogiendo aquí su entierro, como Sansón desdeñado gusta de matar muriendo.» (vv. 2838-2947)

La agresión contra todo lo que le rodea, la búsqueda de la soledad en la tierra y del aislamiento definitivo, la muerte, son signos de la psicosis delirante que atenaza al personaje. Solamente están producidos por la aparición de unos celos inmotivados. La invocación del Orlando furioso ariostesco, enloquecido con la promesa de amor hecha por Angélica a Medoro, lleva a don Luis a cometer una serie de desmanes y a derribar todas las colmenas que con tanto mimo ha estado cuidando. La realidad y el sueño, la vida y la muerte, el ser y el no ser al mismo tiempo... Evidentemente, en el pasaje no hay presencia alguna de un Medoro real. Es un Medoro inventado por la mente atormentada del héroe, que se deja llevar por la tradición ariostesca y añade mecánicamente al nombre de Angélica el del inexistente personaje, sugerido por la tradición textual del poema italiano. La psicosis delirante empuja a don Luis a construir un Medoro, paralelo perfecto del que vive la aventura en el Orlando furioso original. El loco imagina y crea un mundo en el que habitan personajes salidos de la tradición textual y donde se refugia arrastrado por la necesidad de aislarse de la realidad de su entorno.

Cuando los otros personajes ven a don Luis, su reacción es de pánico. Todos le identifican como loco, como ser furioso de quien hay que alejarse y a quien hay que aislar:

«DON PEDRO El colmenero está loco.

La furia incita su pecho, que quien con todos se toma 
Angélica y el desencadenamiento de la locura...

$\begin{array}{ll}\text { FELICIANO } & \begin{array}{l}\text { no puede llamarse cuerdo. } \\ \text { Huye, pues, que despedaza } \\ \text { hasta los árboles recios. }\end{array} \\ \text { FULGENCIO } & \begin{array}{l}\text { Hija, guárdate del loco. } \\ \text { Huid del loco, Fulgencio. } \\ \text { DON PEDRO }\end{array} \\ & \text { Huyen todos.)» (vv. 2948-295) }\end{array}$

Como muy atinadamente dice Covarrubias, el loco habla en exceso y da muchas voces. Estos son los efectos que la locura de los celos produce en esta nueva reencarnación intertextual del héroe de Ariosto:

«Yo soy Orlando el furioso, que en aqueste sitio mesmo le dio Angélica fe y mano a Medoro. El seso pierdo. Loco estoy, pero ¿qué mucho, si me enloquece el veneno de un falso y fingido amor, que pierda prudencia y seso? ¿Estoy vivo? Pero no, que a manos de un desdén muero.

Pues si muerto, ¿cómo hablo?

Si no vivo, ¿cómo siento?

Mas no soy yo, que yo fui

un hombre alegre y contento.

¿Luego soy mi propia sombra?

Sombra no, que tengo cuerpo.

Quizá sueño mis desdichas.»(vv. 2956-2972)

La locura, de don Luis, perfectamente libresca, utiliza también la figura del donaire, Carrasco, como objeto de sus manipulaciones de la realidad. La conexión del galán demente con la realidad se hace a través de la figura del gracioso. Don Luis, ya solos los dos personajes, quiere abrazar a la desaparecida Angélica y la remplaza por Carrasco (vv. 3005-3006). El delirio y las alucinaciones del psicótico le llevan a forjarse un mundo propio, en que toda la realidad es modificada e integrada dentro del modelo literario en el que se apoya su locura. El lacayo reacciona invocando su condición masculina -«iYo Angélica, con más barbas / que un albañil o arriero!»»(vv. 3008-3009)-. En el juego de la utilización del gracioso como objeto rebajado y grotesco, la locura de don Luis le lleva a querer buscar en el pecho de Carrasco la figura de Angélica, de la ausente Angélica: 
«que quiero rasgarte el pecho, porque a mi Angélica dicen la tienes guardada dentro, pues que huyendo de mi furia con Medoro, o con don Pedro, como a Jonás la ballena, te la tragaste.» (vv. 3015-3021)

Carrasco se desabrocha el vestido y don Luis quiere besarle el pecho, llegando a morderle según se desprende del grito del gracioso (v. 3030). La locura de don Luis se centra ahora en la sustitución de Angélica por Carrasco, de su pecho por el del lacayo. El gracioso queda cosificado, cuando él mismo protesta por haber sido tratado como si fuera «turrón o queso» (v. 3035). La escena termina en el momento en que don Luis se dispone a abrir el pecho de Carrasco con «esta daga» (v. 3046). Y el gracioso huye.

El segmento viene a retrasar el momento del desenlace y no añade nada significativo al trenzado del mismo. Margaret Wilson ${ }^{3}$ ya señaló la larga e innecesaria presencia del pasaje que comentamos: "Act III is unnecessarily and tastelessly prolonged by a mad scene, in which poorly motivated jealousy causes Don Luis temporarily to lose his reason. The mood of this scene is out of harmony with what has gone before, and its language is unusually mannered for this period, so that one might be tempted to see it as a later addition, had not the name Angélica given an obvious cue for an imitation of the Orlando furioso".

En conclusión, la lectura detallada de las dos piezas examinadas nos lleva a confirmar lo que adelantábamos en la hipótesis inicial. La psicosis delirante aguda, enmarcada por la fiesta popular y condicionada por la presencia de los gemelos malditos en los mitos creadores de las comunidades humanas, o provocada por una tradición literaria, la del Orlando furioso de Ariosto, se manifiesta de dos maneras diferentes en ambas obras. La Medora dramatiza la desarticulación de las personas de los ridiculizados Acario y Barbarina, y su recuperación final, cuando las bodas se realizan. La villana de la Sagra, atada en su segmento final a la tradición de Ariosto, presenta la súbita transformación del héroe, don Luis, en un ser carente del más elemental sentido de la realidad. Y como todo ha sido un puro ejercicio literario o una broma de Tirso de Molina, vuelve la calma, don Luis recupera el sentido y el final feliz aparece en todo su esplendor. Aunque la obra haya pasado por unos momentos perfectamente inútiles y rigurosamente falsos desde el punto de vista de las necesidades de la dramatización. Todo es falsedad y ficción en el teatro. Esa es su principal virtud. Pero cuando a una falsedad se añade sin necesi- 


\section{Angélica y el desencadenamiento de la locura...}

dad el puro divertimiento literario o el simple y gratuito uso de un recurso artístico muy conocido, el resultado puede ser poco convincente. Como en el caso de La villana de la Sagra.

\section{Notas}

1 Citamos los textos de Medora según nuestra edición de Las cuatro comedias, 2001. Damos el número de las páginas.

2 Usamos los textos de la comedia tal como aparecen en nuestra edición de La villana de la Sagra, 2004. Citamos el número de los versos.

3 Wilson, p. 59.

\section{Bibliografía}

BAJTín, MiJAíl (1970): L'oeuvre de François Rabelais et la culture populaire au Moyen Age et sous la Renaissance, París, París, Gallimard.

CHEVAliER, MAXIME (1966): L'Arioste en Espagne (1530-1650): recherches sur l'influence $d u$ "Roland furieux, Burdeos, Institut d'Études Ibériques et Ibéro-Américaines de l'Université.

GARAPON, ROBERT (1957): La fantaisie verbale et le comique dans le théâtre français du Moyen Age à la fin du XVIIe siècle. París, Armand Collin.

GIRARD, RENE (1972): La violence et le sacré, París, Grasset.

GIRARD, RENE (1978): Des choses cachées depuis la fondation du monde, París, Grasset.

HeRmenegildo, Alfredo (1995): Juegos dramáticos de la locura festiva, Palma de Mallorca, Olañeta.

RUEDA, LOPE DE (2001): Las cuatro comedias. Ed. Alfredo Hermenegildo, Madrid, Cátedra.

Tirso De Molina (2004): La villana de la Sagra. Ed. Alfredo Hermenegildo, Pamplona, Instituto de Estudios Tirsianos.

Wilson, Margaret (1977): Tirso de Molina, Boston, Twayne Publishers. 